\title{
Comparisons and Trends in White-tailed Deer, Odocoileus virginianus, Body Fat in Northeastern Minnesota, 1974-1990
}

\author{
Kerry L. Nicholson ${ }^{1}$, William J. Peterson ${ }^{2,3}$, and WARren B. Ballard ${ }^{1}$ \\ ${ }^{1}$ Department of Natural Resources Management, Texas Tech University, P. O. Box 42125, Lubbock, Texas 79409 USA; e- \\ mail: kernicholson@yahoo.com \\ ${ }^{2}$ Minnesota Department of Natural Resources, Section of Wildlife, P. O. Box 115, Grand Marais, Minnesota 55604 USA; \\ ${ }^{3}$ Retired. Present address: 4601 Lake Creek Road, Troy, Montana 59935 USA
}

Nicholson, Kerry L., William J. Peterson, and Warren B. Ballard. 2008. Comparisons and trends in White-tailed Deer (Odocoileus virginianus) body fat in northeastern Minnesota, 1974-1990. Canadian Field-Naturalist 122(3): 253-261.

The relationships among locations of body fats have not been thoroughly examined in White-tailed Deer (Odocoileus virginianus). We measured bone marrow fat $(n=2995)$, back fat $(n=1018)$, kidney fat $(n=2076)$, and xiphoid fat $(n=1246)$ levels of White-tailed Deer kills from Cook and Lake counties in northeastern Minnesota during 1974-1990. For each dead deer we determined age, sex, date, and causes of mortality. All of the fat measures were correlated to varying degrees. Generally all fat measurements peaked in late autumn and subsequently began declining and reached their lowest levels in May. Fat content was negatively correlated with winter severity. Causes of mortality included predation, poaching, accidental, unknown, and auto-collisions. Predated animals had lower bone marrow (-7.42 \pm 3.92$)$ and $0.165 \pm 2.30$ times lower back fat and had higher amounts of kidney fat than those killed by vehicles $(0.86 \pm 0.43)$.

Key Words: White-tailed Deer, Odocoileus viriginanus, bone marrow, kidney, mobilization, mortality, winter severity, xiphoid, Minnesota.

Physical condition is important to ungulate survival and reproduction. Poor nutritional status can often result in reduced body size, reduced antler growth, decreased reproduction, and increased mortality. Fat storage reflects the annual nutritional cycle which is why fats throughout the body are used as a general index for body condition. Wildlife managers often assess an individual's body condition as a tool for management decisions regarding populations.

In 1971 a White-tailed Deer (Odocoileus virginianus) reproduction study was initiated to monitor fawn production and estimate survival. Initially this was done by managers who examined vehicle-killed deer to obtain age classes, qualitative description of fat reserves, number of fetuses carried if applicable, and body weights. We also collected data on sex and cause of mortality, and measured several types of body fat (i.e., back fat, kidney fat, bone marrow fat, and xiphoid fat) to assess relative condition. The purpose of this paper is to examine fat relationships.

Several studies have correlated kidney fat with marrow fat (Finger et al. 1981; Torbit et al. 1988; Takatsuki 2000) and correlated several different bones with regards to marrow fat (Snider 1980; Ballard et al. 1981; Fuller et al. 1986; Davis et al. 1987; Husseman et al. 2003). However, few studies have examined relationships among the other types of body fat indices with bone marrow fat. Lochmiller et al. (1985) indicated that kidney fat and femoral marrow fat together made a good assessment of body condition. Finger et al. (1981) suggested that adding subcutaneous back fat to aforementioned parameters would provide a more accurate measurement of body condition. Several other studies suggested that the most accurate evaluation of physical condition can be attained by measuring two or more indicators (Ransom 1965; Trout and Thiessen 1968; Winstanley et al. 1998), but others indicate that marrow fat may not be useful (Mech and DelGiudice 1985; Cook et al. 2001).

We examined differences in fat content of Whitetailed Deer by age classes, sex, month, year, winter severity index (WSI) and causes of death. We hypothesized deer in poor body conditions (i.e., low body fat) would be targeted by predators.

\section{Study Area}

We conducted the study in Cook and Lake counties in northeastern Minnesota near Lake Superior during 1974-1990. All but a small number of deer in the region migrated to this area each winter. Elevation ranged from 180 to $700 \mathrm{~m}$ and the climate was cool-temperate (Hovde 1941), with snowfall averaging $>150 \mathrm{~cm}$ during winter (Nelson and Mech 1981). The general area along Lake Superior was milder and had less snow depth than the inland area, where the weather station was located. The area where temperatures were recorded was $<50 \mathrm{~m}$ from Lake Superior, which gets full benefit of the lake's "heat sink" effect such that the surrounding area is kept warmer in winter and cooler in summer than the inland areas. For a more detailed description of the study area, refer to Nelson and Mech (1981).

\section{Methods}

We collected data on all dead deer that were found during 1974-1990 in Cook and Lake counties. We 
TABLE 1. Fat type, age class, gender, sample size, mean and fat (SD) of White-tailed Deer, northeastern Minnesota 1974-1990.

\begin{tabular}{lccccccc}
\hline \hline Fat & Age Class & Male $(n)$ & Mean & $($ SD $)$ & Female $(n)$ & Mean & SD \\
\hline Kidney & $\mathrm{A}$ & 106 & 2.80 & $(1.28)$ & 580 & 3.81 & $(1.33)$ \\
& $\mathrm{F}$ & 471 & 3.02 & $(1.37)$ & 479 & 3.21 & $(1.38)$ \\
Xiphoid & $\mathrm{Y}$ & 167 & 3.01 & $(1.49)$ & 273 & 3.51 & $(1.41)$ \\
& $\mathrm{A}$ & 41 & 4.07 & $(4.98)$ & 249 & 5.84 & $(5.43)$ \\
& $\mathrm{F}$ & 224 & 2.94 & $(3.42)$ & 198 & 3.16 & $(3.64)$ \\
Back & $\mathrm{Y}$ & 82 & 4.79 & $(4.45)$ & 128 & 4.74 & $(4.85)$ \\
& $\mathrm{A}$ & 46 & 6.80 & $(10.62)$ & 274 & 12.46 & $(12.67)$ \\
& $\mathrm{F}$ & 246 & 4.89 & $(6.61)$ & 214 & 4.74 & $(6.33)$ \\
Marrow & $\mathrm{Y}$ & 93 & 10.24 & $(12.36)$ & 145 & 9.68 & $(11.49)$ \\
& $\mathrm{A}$ & 148 & 77.27 & $(20.64)$ & 886 & 82.69 & $(19.63)$ \\
& $\mathrm{F}$ & 669 & 71.59 & $(23.43)$ & 659 & 73.04 & $(22.54)$ \\
\hline \hline
\end{tabular}

examined each deer for sex, age (tooth eruption and replacement and by counts of dental cementum when tooth replacement was completed), and fat composition. We assigned a date of death. We classified deer as fawn (0-11.5 months), yearling (12-23.5 months), adult $\geq 24)$. We assumed all fawns were born on 1 June.

We removed femur bone marrow fat samples from the center of the bone and froze them until processed. We determined marrow fat conditions according to methods described by Neiland (1970). We also made several body fat measurements to compare with marrow fat contents. We estimated kidney fat based on the following criteria: (1) bare of fat, (2) slightly spotted to nearly bare of fat, (3) spotted with fat, (4) heavily spotted to nearly enveloped in fat, and (5) kidney completely enveloped in fat. We initiated the study measuring bone marrow and kidney fat; we began measuring xiphoid fat on the xiphoid process in December 1984, and back fat in August 1982. We measured xiphoid fat in $\mathrm{mm}$ with calipers. We measured back fat depth ( $\mathrm{mm})$ on the rump about $40 \mathrm{~mm}$ forward of the base of the tail and $20 \mathrm{~mm}$ to the side of the spine. Some fat measurements were not taken on all deer due to severity of vehicle impact, degree of decomposition, or because of consumption by predators or scavengers.

We classified cause of death into four categories: based upon the evidence at the site: predator, poaching, accidental, and vehicle. Winter severity was documented for each year using the Minnesota Department of Natural Resources (MDNR) index for the Grand Marais area (MDNR, unpublished data). The WSI was obtained by summing the number of days with $\geq 15$ inches of snow and the number of days of $-17^{\circ} \mathrm{C}$, or below (MNDR, unpublished data). The temperatures and snow depths were taken at the official weather station.

Xiphoid and back fat were natural log transformed for most analyses; however, they were not transformed for the time series analysis. Kidney fat was measured on a scale so we used Spearman's rho to determine fat correlation. We used an LSMeans Con- trast to determine if animals that died from predation or poaching had significantly different fat levels from those killed by vehicles. Fat data missing prior to when collections began for specific fat types could not be used for comparisons among the fat types, but could be utilized in analysis related to winter severity. For this analysis, in order to reduce the variation due to sample size discrepancy by mortality type, we randomly sub-sampled the 2912 vehicle collisions to 275 samples (Table 2).

We used the Autoreg procedure in SAS (SAS Institute Inc. Cary, North Carolina USA 2000) to analyze the time series analysis to determine significant explanatory variables in fat deposition and mobilization. We summarized the data with mean values of fat per month and then subjected to the time series analysis. The model included winter severity index (WSI), age class, and sex. The Autoregressive parameters were selected using the stepwise back step option.

\section{Results}

We collected 2995 samples of bone marrow, 1018 back fat samples, 2076 kidney fat samples, and 1246 xiphoid fat samples (Table 1). All of the fat measures were correlated to varying degrees. Xiphoid and back fat were the most similar in measures $\left(r_{s}=0.87\right)$. Kidney fat was also highly similar to marrow $\left(r_{s}=0.6\right)$, back $\left(r_{s}=0.81\right)$, and xiphoid $\left(r_{s}=0.75\right)$. The least correlated fats were bone marrow with xiphoid $\left(r_{s}=0.66\right)$ and back fat $\left(r_{s}=0.69\right)$. All of the fat types were negatively correlated with winter severity $(r=-0.19$ marrow; $r=-0.15$ xiphoid; $r=-0.12$ back; $r=-0.15$ kidney).

Time series model for mean bone marrow improved when age, sex, and WSI were added $\left(r^{2}=0.6\right.$; with 3 parameters $r^{2}=0.63$ ) with 3 autocorrelated parameters. After accounting for variation in fat across years due to the autocorrelated parameters by using time series analysis, age and WSI were significant factors in bone marrow fat (age: $t_{1}=3.41, P<0.001$; WSI: $\left.t_{1}=-2.11, P=0.04\right)$. As animals got older they had 
TABLE 2. Mean fat and standard error by mortality type with sample sizes of White-tailed Deer, northeastern Minnesota 1974-1990.

\begin{tabular}{llrrrc}
\hline \hline Mortality (n) & Variable & Mean & $($ SE) & $t$ & $P$-value \\
\hline \multirow{3}{*}{ Predation (34) } & & & & & Vehicle vs. Predation \\
& Marrow & 70.12 & $(3.70)$ & -1.89 & 0.059 \\
& Xiphoid & 3.38 & $(2.10)$ & 0.04 & 0.96 \\
& Back & 1.82 & $(1.38)$ & -2.16 & $0.035^{*}$ \\
& Kidney & 2.90 & $(0.34)$ & 2.67 & $0.008^{*}$ \\
Vehicle (275) & & & & Vehicle vs. Poaching \\
& Marrow & 76.6 & $(0.40)$ & 1.66 & 0.096 \\
& Xiphoid & 3.39 & $(1.03)$ & 0.89 & 0.38 \\
Poaching (20) & Back & 4.14 & $(1.04)$ & 0.58 & $0.045^{*}$ \\
& Kidney & 3.34 & $(0.03)$ & 2.01 & $(4.69)$ \\
& Marrow & 69.10 & & \\
& Xiphoid & 9.97 & $(2.27)$ & & \\
& Back & 15.64 & $(1.35)$ & & \\
\hline \hline
\end{tabular}

* Significantly different from an $\alpha=0.05$

Means and standard error for back fat and xiphoid fat are from back transformed natural log data.

more fat and during the colder months their marrow fat decreased. After accounting for variation across years, there was evidence that age and sex were significant for mean kidney fat $\left(r^{2}=0.82\right.$, age: $t_{1}=2.46$, $P=0.02$; sex: $\left.t_{1}=1.91, P=0.06\right)$. Only $59 \%$ of the variation was explained by the time series model for mean back fat with three autocorrelated parameters. There was conclusive evidence that sex and WSI influenced mean back fat (sex: $t_{1}=3.98, P<0.001$; WSI: $\left.t_{1}=-2.83, P=0.04\right)$. Back fat also was influenced by the time parameter $\left(t_{1}=-3.28, P<0.001\right)$. The time series model explained $82 \%$ of the variation in mean xiphoid fat with three autocorrelated parameters. There was slight evidence that WSI was influential on mean xiphoid fat $\left(t_{1}=-1.85, P=0.07\right)$. Looking at each fat over all years of the study, there is a slight decreasing trend in fat content in deer, however this was only significant for back fat (back: $-0.71 \pm 0.21, P=0.002$; Figure 1).

Fat measures were greater for poached animals and lower for predated animals when compared with vehicle collision individuals, although this was only statistically significant for kidney fat, bone marrow and back fat (Table 2). Predated animals had lower bone marrow $(-7.42 \pm 3.92)$ and $0.165 \pm 2.30$ times lower back fat than those that were killed by vehicles (Figure 2). Poached animals had higher amounts of kidney fat than those killed by vehicles $(0.86 \pm 0.43)$. Due to the distribution of sample collection, we were unable to directly compare fat content of poached versus predated individuals.

Mobilization and deposition trends were similar throughout a year for all fats; therefore, we used one or two fats as examples of the trends. All deer had cyclic use of fats, decreasing fat amounts in spring (AprilJune) and increasing or storing over the summer and fall to the highest levels in the winter (November-
January) to again decrease in the spring. Females had more fat than males (Figure 3), and fawns and yearlings had lower amounts of body fat than adults (Figure 4). There was an inverse relationship between WSI and fat amounts (Figure 5).

\section{Discussion}

All fats were associated with each other to varying degrees. Back and xiphoid fats were highly correlated; kidney fat was also correlated with back and xiphoid fat. Bone marrow fat was largely explained by the other measures as well, though it was most different from the others, especially kidney fat. This was likely due to the asymptotic pattern rather than a strictly linear pattern that bone marrow exhibits. The trends in body condition that we detected were similar to those reported in other species comparing sex and age classes, seasonal differences, and causes of death (Franzmann and Arneson 1976; Davis et al. 1987; Spears et al. 2003).

Fat is deposited and mobilized throughout the body in a specific order (Kistner et al. 1980; Winstanley et al. 1998). Mobilization occurs in the order of subcutaneous fat, various fats throughout the abdominal cavity, and then bone marrow fat, whereas the deposition occurs in the reverse order (Harris 1945; Winstanley et al. 1998). Each fat index has limitations that can not only be due to physiological factors, biological factors, and season influences, but also can be due to collection techniques, for example, bone marrow fat is the first fat deposited and last fat reserve used by an organism; therefore, it is an excellent index for an animal in extremely poor body condition, but a poor index for animals in good condition (Mech and DelGiudice 1985; Fuller et al. 1986; Torbit et al. 1988). Another consideration is what constitutes a healthy animal in one region may be relative to other members of the popu- 


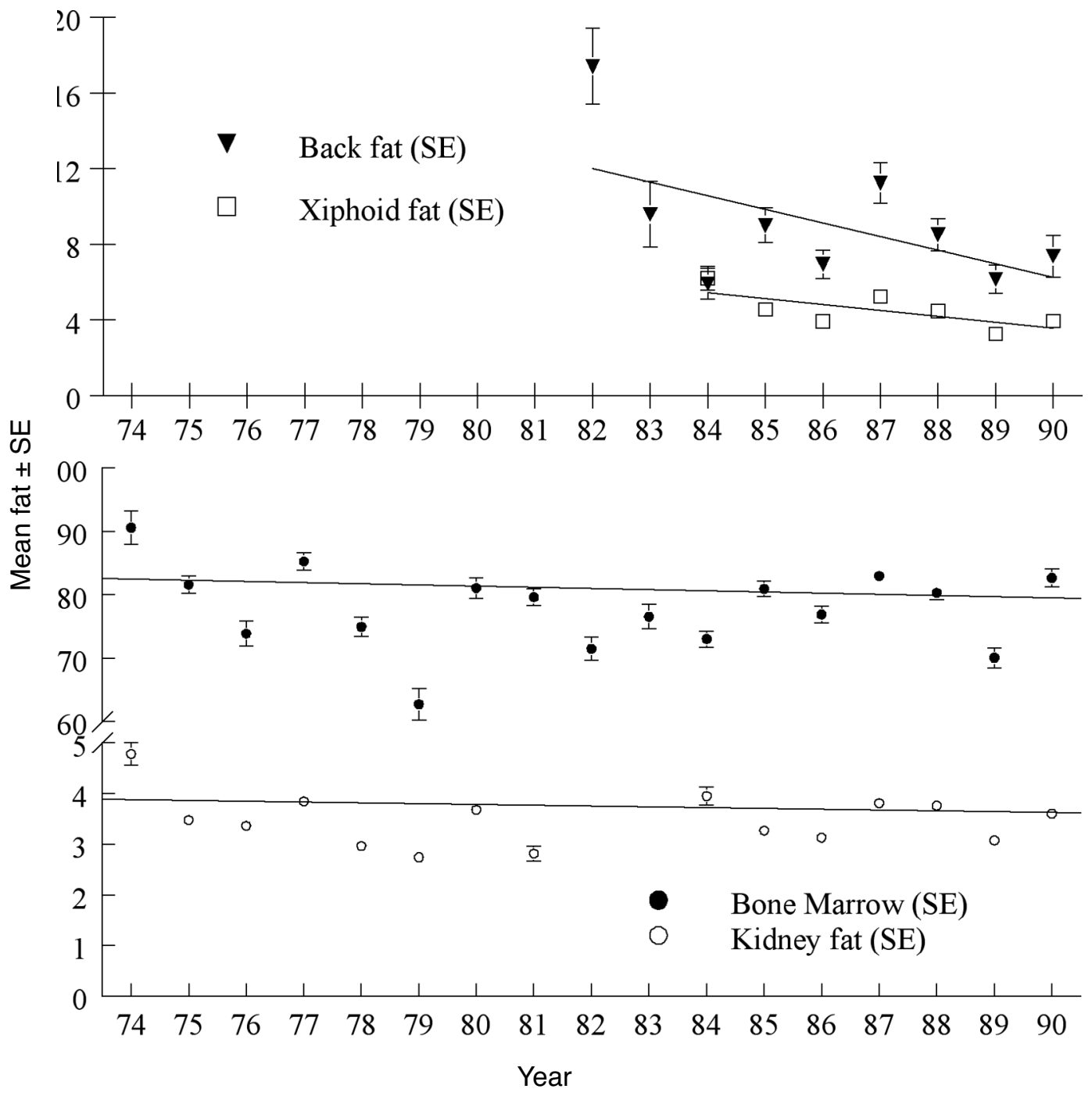

FIGURE 1. Mean fat over years of back, xiphoid, bone marrow and kidney fat from White-tailed Deer in Minnesota (1974-1990).

lation or region (Ballard 1995). Previous research indicates that marrow from other bones throughout the body may be used when the femur is not available (i.e., predation sites) and those different marrow fats are correlated to one another (Snider 1980; Ballard et al. 1981; Fuller et al. 1986; Davis et al. 1987).

Subcutaneous fats, like back fat and xiphoid fat, are deposited and mobilized in the reverse of marrow fat (Harris 1945). It is the last fat put on the body, and the first fat used. Therefore, it is only an indicator for animals which are in good condition (Harris 1945). Unlike other fats, during high stress conditions subcutaneous fats can be mobilized simultaneously from all areas of the body (Kistner et al. 1980). Back fat can be a diffi- cult measurement to collect due to the prime location for consumption by predators and by hunter reluctance. If managers are surveying fat content at check stations in the autumn during optimal fat periods, hunters can be uncooperative by not allowing back fats to be measured due to the considerable skinning needed to obtain the measurement (Austin 1984). Recent development of ultrasound methods may alleviate the problem (Stephenson et al. 2002). However, most of our data were obtained from vehicle collisions, and therefore, back fat was usually so highly damaged from the impact that accurate measurements were impossible. Austin (1984) suggested that xiphoid fat can be a good substitute for back fat, which our data supports. 

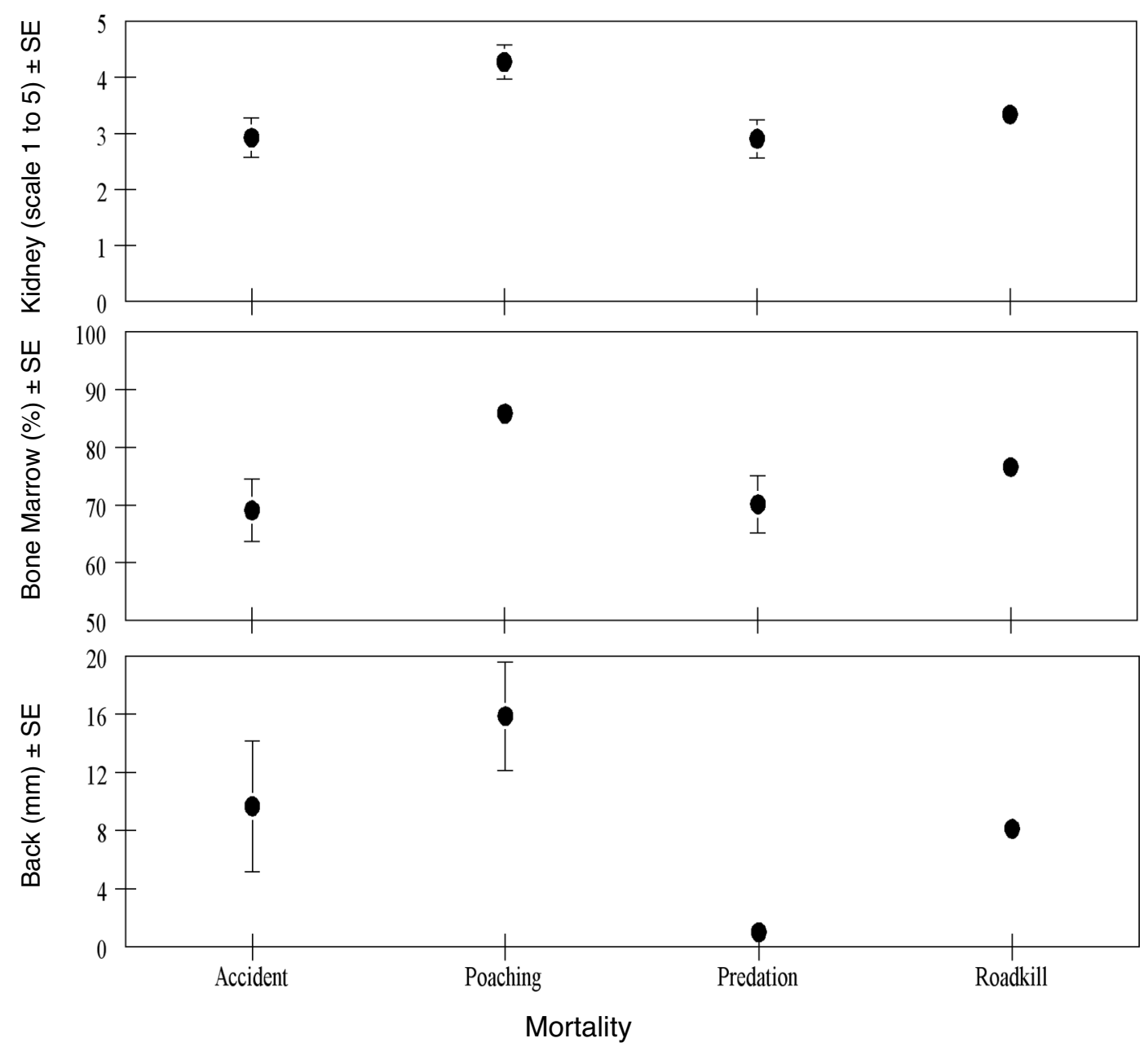

FIGURE 2. Fat measures by mortality type from kidney, back and bone marrow from White-tailed Deer in northeastern Minnesota (1974-1990).

Several studies have correlated kidney fat with marrow fat (Finger et al. 1981; Torbit et al. 1988; Takatsuki 2000) and correlated several different bones with regards to marrow fat (Snider 1980; Ballard et al. 1981; Fuller et al. 1986; Davis et al. 1987; Husseman et al. 2003). However, few studies have examined relationships among the other types of body fat indices with bone marrow fat. Lochmiller et al. (1985) indicated that kidney fat and femoral marrow fat together made a good assessment of body condition. Finger et al. (1981) suggested that adding subcutaneous back fat to aforementioned parameters would provide a more accurate measurement of body condition.

These data were not collected to examine impacts of global warming. However, they could be used in conjunction with other metadata analyses to examine possible impacts on mammalian species. There was a slight decreasing trend of each fat amount, though it was only significant for back fat (Figure 1). This significance is primarily influenced by the data point from 1982. There are several possible explanations as to what happened in 1982 . The previous winter severity was low (1981 WSI $=72)$; therefore, the animals had a relatively "easy" winter and a "good" amount of fat. The winter severity was high during 1982 $($ WSI $=142)$ and with the time lag the results of this severe winter would be seen after 1983; thus the decrease in fat content the following year. However, even with a lighter WSI the following years $(1983=46$; $1984=85 ; 1985=42$ ), the fat content still did not increase. For all of the fats there is a slight negative trend over time. Changes in temperature can cause a change in species traits by shifting their ranges (Hughes 2000; Root et al. 2003), changing natural history traits, or 

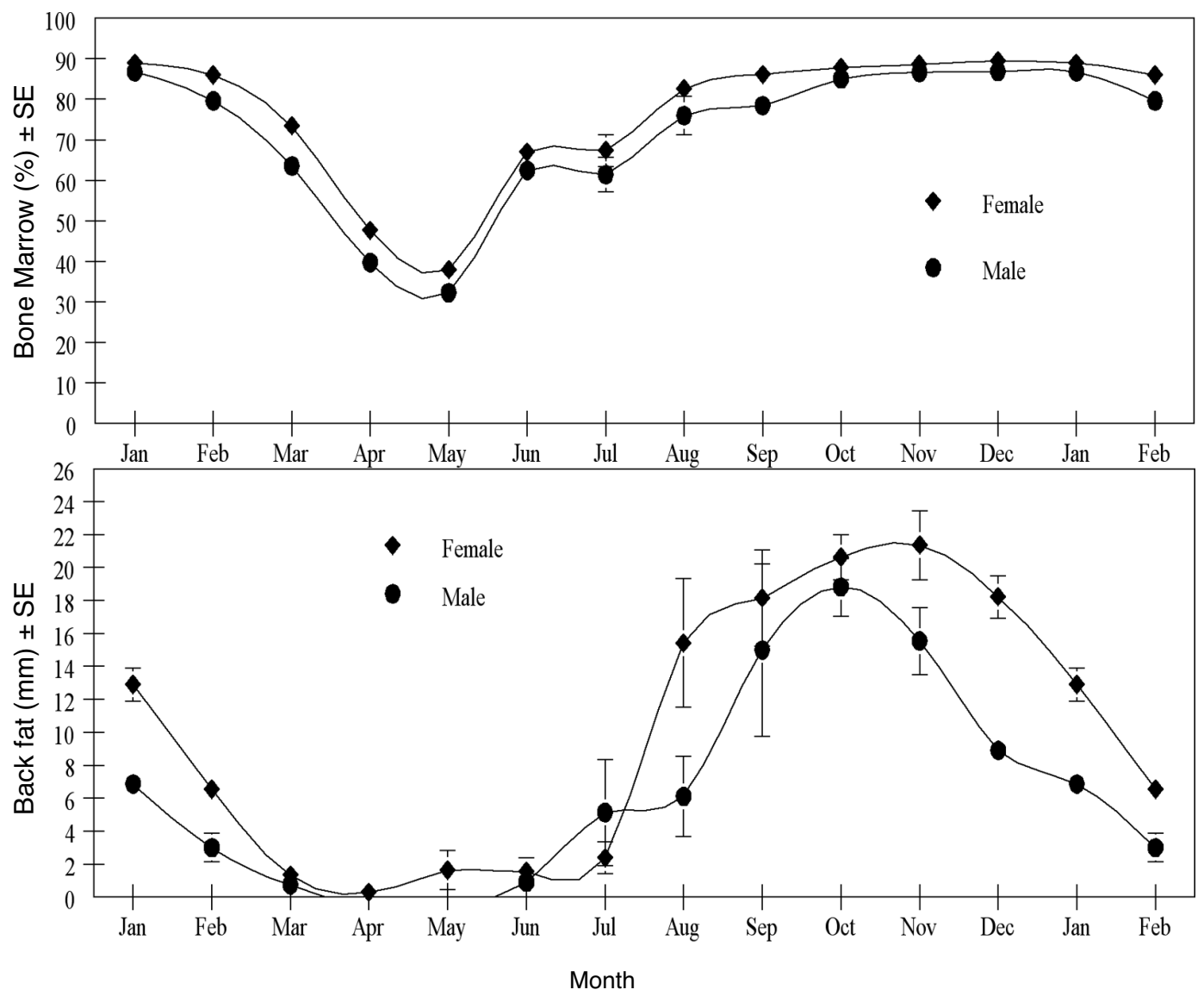

FIGURE 3. Mean bone marrow and back fat by sex averaged across months from White-tailed Deer in northeastern Minnesota (1974-1990).

changes in morphology (Barnosky et al. 2003; Root et al. 2003).

Predator-prey relationships have been discussed extensively through the years, yet what is still uncertain is the underlying mechanism of predicting predation mortality (Quinn and Cresswell 2004). One foraging theory of predators is they preferentially select the more vulnerable prey (e.g. Schaller 1972; Scheel 1993; Moore 2002; Khan et al. 2004). Vulnerability of an individual is typically defined by the age and health of the individual (Bergman et al. 2006). Determining differential selection is difficult because predation events are rarely witnessed and then it is even more complicated for biologists to determine the ultimate versus proximate cause of death. Our data suggest that the predated white-tail deer were in lower body condition than those that were randomly killed by vehicles. There is no indication that animals with low body fat preferred road travel.

Biologists will continue to debate the usefulness of traditional body fat estimates for assessing body condition at time of death (e.g., Mech and DelGiudice
1985; Watkins et al. 1991; DelGiudice et al. 1992; Mech 2007). New technologies such as ultrasonography undoubtedly will improve the determination of estimation of body condition (Smith and Lindzey 1982; Stephenson et al. 2002). However, field biologists often may not have access to new technologies and will probably continue to rely on the traditional forms of condition assessment. Our results suggest that traditional fat measurements can provide reasonable indices of body condition between sexes, among age classes, differences among years, and in relation to winter severity and causes of death. All of the fat measurements were correlated and appeared useful, but a combination of four measurements may be superior for estimating condition.

\section{Acknowledgments}

Data for this paper were collected while Peterson was employed by the Minnesota Department of Natural Resources, Section of Wildlife, as Area Wildlife Manager at Grand Marais, Minnesota. He appreciates having been permitted the freedom of action to 

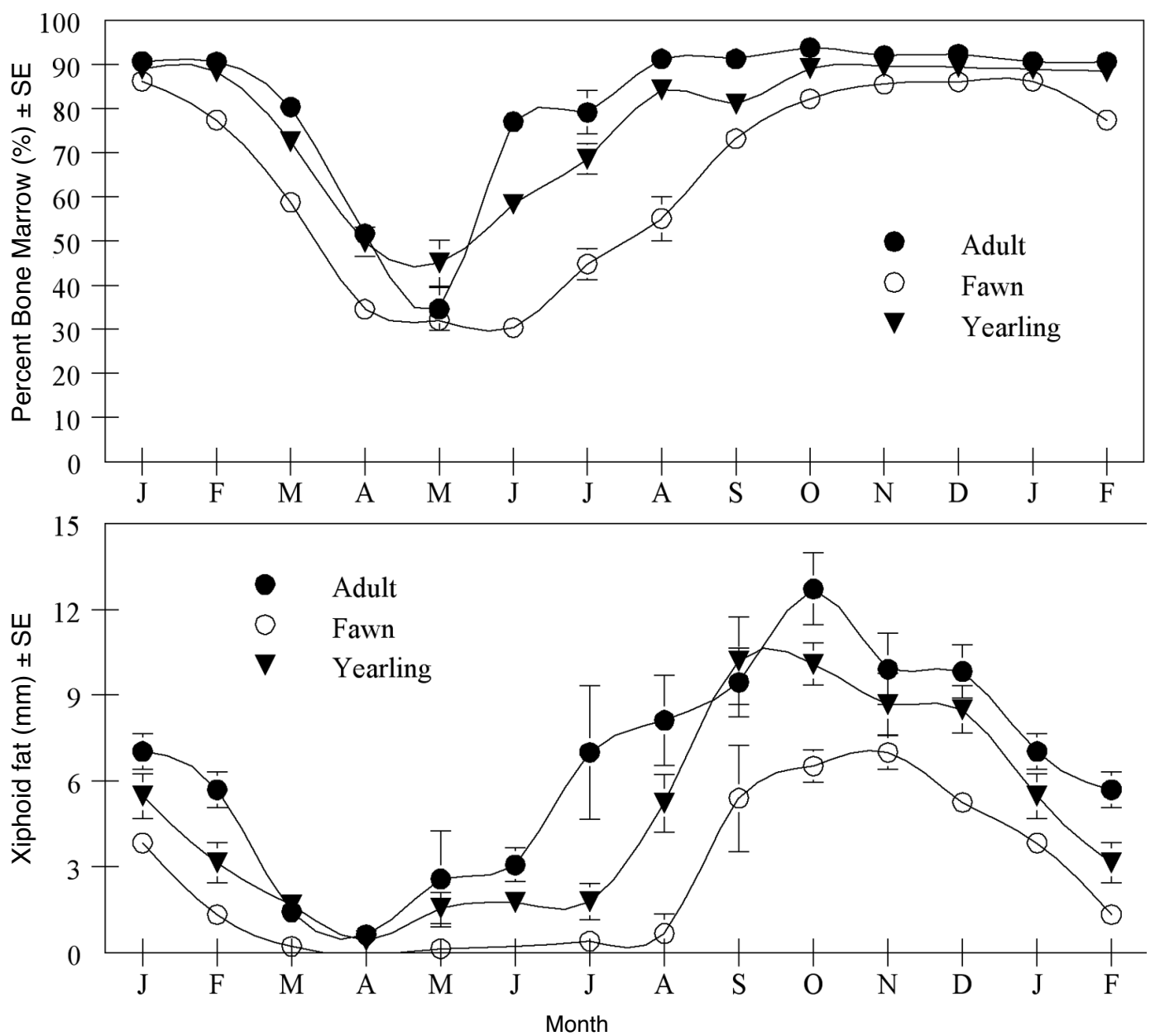

FIGURE 4. Mean bone marrow and xiphoid fat by age class averaged across months from White-tailed Deer in northeastern Minnesota (1974-1990).

pursue this and other studies that were not covered by formal research proposals. Thanks are extended to R. Fields, and T. Webb who helped collect data, and to P. Coy, who processed marrows in the early years of the study. Special thanks are due his wife, Dale, who gave up many nights, weekends, and holidays to help examine deer and collect samples in addition to putting up with having her oven used for drying marrows. Thanks to M. Borgstrum with the University of Arizona's Research Computing Support Group for statistical consults. This is Texas Tech University, College of Agricultural Sciences and Natural Resources technical publication T-9-1131.

\section{Literature Cited}

Austin, D. 1984. Fat depth at the xiphoid process - a rapid index to deer condition. Great Basin Naturalist 44: 178181.
Ballard, W. B. 1995. Bone marrow fat as an indicator of ungulate condition-how good is it? Alces 31: 105-109.

Ballard, W. B., C. L. Gardner, and J. H. Westlund. 1981. Use of mandible versus long bone to evaluate percent marrow fat in moose and caribou. Proceedings of the North American Moose Conference Workshop 17: 147-164.

Barnosky, A. D., E. A. Hadly, and C. J. Bell. 2003. Mammalian response to global warming on varied temporal scales. Journal of Mammalogy 84: 354-368.

Bergman, E. J., R. A. Garrott, S. Creel, J. J. Borkowski, R. Jaffe, and F. G. R. Watson. 2006. Assessment of prey vulnerability through analysis of wolf movements and kill sites. Ecological Applications 16: 273-284.

Cook, R. C., J. G. Cook, D. L. Murray, P. Zager, B. K. Johnson, and M. W. Gratson. 2001. Development of predictive models of nutritional condition for Rocky Mountain Elk. Journal of Wildlife Management 65: 973-987.

Davis, J. D., P. Valkenburg, and D. J. Reed. 1987. Correlation and depletion patterns of marrow fat in caribou bones. Journal of Wildlife Management 51: 365-371. 


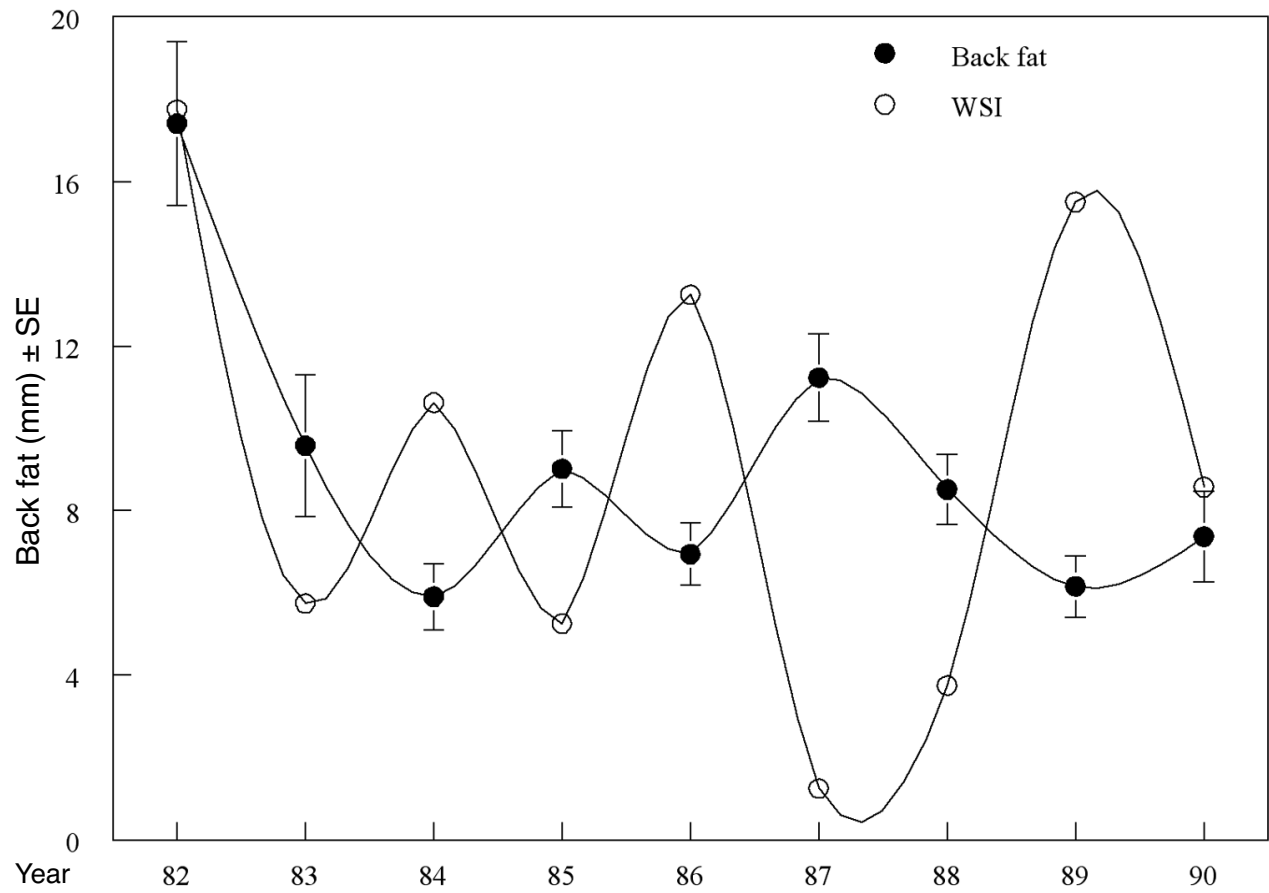

FIGURE 5. Mean back fat in comparison to winter severity indices (WSI) across years from White-tailed Deer in northeastern Minnesota (1974 - 1990).

DelGiudice, G. D., L. D. Mech, K. E. Kunkel, E. M. Gese, and U. S. Seal. 1992. Seasonal patterns of weight, hematology, and serum characteristics of free-ranging female white-tailed deer in Minnesota. Canadian Journal of Zoology 70: 974-983.

Finger, S. E., I. L. Brisbin, Jr., and M. H. Smith. 1981. Kidney fat as a predictor of body condition in whitetailed deer. Journal of Wildlife Management 45: 964-968.

Franzmann A. W., and P. D. Arneson. 1976. Marrow fat in Alaskan moose femurs in relation to mortality factors. Journal of Wildlife Management 40: 336-339.

Fuller, T. K., P. L. Coy, and W. J. Peterson. 1986. Marrow fat relationships among leg bones of white-tailed deer. Wildlife Society Bulletin 14: 73-75.

Harris, D. 1945. Symptoms of malnutrition in deer. Journal of Wildlife Management 42: 334-351.

Hovde, M. R. 1941. Climate of Minnesota. Pages 925-934 in Climate and man. Yearbook of Agriculture. United States Government Printing Office, Washington, D.C., 1248 pages.

Hughes, L. 2000. Biological consequences of global warming: is the signal already apparent? Trends in Ecology and Evolution 15: 56-61.

Husseman, J. S., D. L. Murray, G. Power, and C. M. Mack. 2003. Correlation patterns of marrow fat in Rocky Mountain elk bones. Journal of Wildlife Management 67: 742-746.

Khan, Q. J. A., E. Balakrishnan, and G. C. Wake. 2004. Analysis of a predator-prey system with predator switching. Bulletin of Mathematical Biology 66: 109-123.
Kistner, T. P., C. E. Trainer, and N. A. Hartmann. 1980. A field technique for evaluating physical condition of deer. Wildlife Society Bulletin 8: 11-17.

Lochmiller, R. L., E. C. Hellgren, W. E. Grant, and L. W. Varner. 1985. Bone marrow fat and kidney fat indices of condition in collared peccaries. Journal of Mammalogy 66: 790-795.

Mech, L. D. 2007. Femur-marrow fat of White-tailed deer fawns killed by Wolves. Journal of Wildlife Management 71: 920-923.

Mech, L. D., and G. D. DelGiudice. 1985. Limitations of the marrow-fat technique as an indicator of body condition. Wildlife Society Bulletin. 13: 204-206.

Moore, J. 2002. Parasites and the Behaviour of Animals. Oxford University Press, Oxford.

Neiland, K. A. 1970. Weight of dried marrow as indicator of fat in caribou femurs. Journal of Wildlife Management 34: 904-907.

Nelson, M. E., and L. D. Mech. 1981. Deer social organization and wolf predation in northeastern Minnesota. Wildlife Monograph 77. 53 pages.

Quinn, J. L., and W. Cresswell. 2004. Predator hunting behavior and prey vulnerability. Journal of Animal Ecology 73: 143-154.

Ransom, A. B. 1965. Kidney and marrow fat as indicators of white-tailed deer condition. Journal of Wildlife Management 29: 397-398.

Root, T. R., J. T. Price, K. R. Hall, S. H. Schneider, C. Rosenzweig, and J. A. Pounds. 2003. Fingerprints of global warming on wild animals and plants. Nature 421: $57-60$. 
Schaller, G. B. 1972. The Serengeti Lion: A Study of Predator Prey Relations. University of Chicago Press, Chicago.

Scheel, D. 1993. Watching for lions in the grass - the usefulness of scanning and its effects during hunts. Animal Behaviour 46: 695-704.

Smith, R. B., and F. G. Lindzey. 1982. Use of ultrasound for detecting pregnancy in mule deer. Journal of Wildlife Management 46: 1089-1092.

Snider, J. B. 1980. An evaluation of mandibular fat as an indicator of condition in moose. Proceedings of the North American Moose Conference Workshop 16: 37-50.

Spears, B. L., W. J. Peterson, and W. B. Ballard. 2003. Bone marrow fat content from moose in northeastern Minnesota, 1972-2000. Alces 39: 273-285.

Stephenson, T. R., V. C. Bleich, B. M. Pierce, and G. P. Mulcahy. 2002. Validation of mule deer body composition using in vivo and post-mortem indices of nutritional condition. Wildlife Society Bulletin 30: 557-564.
Takatsuki, S. 2000. Kidney fat and marrow fat indices of the sika deer population at Mount Goyo, northern Japan. Ecological Research 15: 453-457.

Torbit, S. C., L. H. Carpenter, R. M. Bartmann, A. W. Alldredge, and G. C. White. 1988. Calibration of carcass fat indices in wintering mule deer. Journal of Wildlife Management 52: 582-588.

Trout, L. E., and J. L. Thiessen. 1968. Reagent dry assay of marrow fat in white-tailed deer. Journal of Wildlife Management 37: 103-105.

Watkins, B. E., J. H. Witham, D. E. Ullrey, D. J. Watkins, and M. J. Jon. 1991. Body composition and condition evaluation of White-tailed Deer fawns. Journal of Wildlife Management 55: 39-51.

Winstanley, R. K., G. Saunders, and W. A. Buttemer. 1998. Indices for predicting total body fat in red foxes from Australia. Journal of Wildlife Management 62: 1307-1312.

Received 23 April 2008

Accepted 31 March 2009 